\title{
How to train our healthcare professionals in resuscitation: A suggested plan
}

\author{
Tariq Hayat Khan, MCPS, FCPS \\ Consultant Anesthesiologist \& Pain Specialist, \\ President, Pakistan Resuscitation Society (PARES), Islamabad, Pakistan.
}

Correspondence: Dr. Tariq Hayat Khan, APICAREHQ, 25-E, Ibn-e-Sina Road, G-10/3, Islamabad, Pakistan; Cell: +92 321 5149709; E-mail: apicarejournal@gmail.com; apicare@yahoo.com

\section{Abstract}

Cardiopulmonary resuscitation (CPR) is a part of physiology curriculum, which is taught in the first two years of medical education. In the next three years medical undergraduates study the diseases and their treatment, which also includes cardiac and/or pulmonary arrest due to any cause, and its management. Unluckily, the lack of emphasis on practical training results in all graduates to be raw as far as resuscitation is concerned. The resuscitation looks not to be on priority in our country, so except sporadic individual effort on training, there is no organized effort, nor any central body responsible for it. It is a very sad state of affairs, and needs to be focus of attention at all appropriate levels. This editorial is an overview of the necessity, the current situation in Pakistan and a suggested plan to improve the stats of trained resuscitators, with the ultimate aim to take it to the high school level.

Key words: Cardiopulmonary resuscitation; CPR; BLS; ALS; Training, hands-on

Citation: Khan TH. How to train our healthcare professionals in resuscitation: A suggested plan. Anaesth. pain intensive care 2020;24(4):377-382.

Received: 21 July 2020, Reviewed: 30 July 2020, Accepted: 6 August 2020

\section{Introduction}

Cardiovascular diseases comprise over $40 \%$ of all disease burden in the world. These have been the leading cause of death in many countries. An estimated 17.9 million lives are lost each year due to heart diseases out of a total of 57.029 million deaths in the world. Another $9.66 \%$ are caused by cerebrovascular disease. Ischemic heart disease was the cause of over three million deaths in developed countries, while in developing countries the figures were over two million. According to an estimate $30 \%$ of all deaths in Pakistan are due to cardiovascular causes. ${ }^{1}$

No age is immune to heart disease. It may affect young children to adolescents to middle aged people. The mean age of cardiovascular disease among armed forces service personnel has been witnessed to be gradually falling. In a recent study conducted in AFIC/NIHD, from Oct 2018 to Jun 2019, $57.8 \%$ (148) cases from age group of 35-45 years were found with abnormal ETT. $76.6 \%$ of these had normal CT angiography and $10.2 \%$ cases had any pattern of critical disease. $^{2}$

Main risk factors have been identified to be lack of regular exercise $40.4 \%$, overweight $33.7 \%$, hypertension $20.2 \%$, hypercholesterolemia $19.2 \%$, smoking $13.5 \%$, diabetes mellitus $7.7 \%$, and obesity $5.8 \% .^{3}$

Cardiopulmonary arrest may occur everywhere, inside hospital departments, most commonly observed in high care dependent areas, e.g., emergency room (ER), operating rooms (ORs) and intensive care areas (ICUs).

Each year, more than 350,000 out-of-hospital cardiac arrests occur in the United States. ${ }^{4}$ Cardiac arrest includes cardiac standstill as well as ventricular fibrillation. In both conditions survival of the victim 
will depend upon immediate CPR from someone nearby. It has been estimated that $90 \%$ of victims of out-of-hospital cardiac arrest will die. CPR needs to be performed immediately in the first few minutes of cardiac arrest, when it may double or triple the chances of survival of the victim. ${ }^{4}$

To enhance the chances of survival of cardiac arrest victims by first responders, we need to train a sizable proportion of our population. Many advanced countries have developed very elaborate system of training, starting with the school CPR training program for the school children to organized programs for general public and even factory workers. Ambulance drivers, police officers, coast guards, firefighters are the usual group which are required to get formal training. In most of the countries training and certification institutions have been established as NGO's or semi-official organizations. In USA, the leading role is being played by American Heart Association (AHA). Many other agencies are also active, e.g., American Red Cross, National Safety Council and American Safety \& Health Institute. In UK, Resuscitation Council (UK) is an official agency responsible for training.

Resuscitation has many types and each type is meant to address a different scenario, and is learnt by individuals based upon to their knowledge and expertise. For all healthcare providers (HCPs), Basic Life Support (BLS) is the basic thing. Advance life Support (ALS) program is reserved for all graduate / postgraduate doctors and nursing staff, especially those working in emergency rooms (ER), operating rooms (ORs), and various types of intensive care units (ICUs). It aims to enhance the skills of the HCPs dealing with emergencies, in managing the victims of in-hospital cardiac arrest or other cardiopulmonary diseases. The special emphasis is laid on prompt identification of ventricular fibrillation, ventricular tachycardia and many other life-threatening arrhythmias and to start prompt intervention. 5,6

\section{The Current Status}

\subsection{Rescue 1122}

Pakistan has a good example of Rescue 1122, an official organ of Punjab Emergency Service, the staff of which has been trained in first aid, BLS and many emergency procedures. It was established under the
Punjab Emergency Service Act, promulgated in 2006 to provide legal cover to the Emergency Services Reforms initiated in 2004 from Lahore. Rescue 1122 is available in 36 districts of Punjab, and responds to millions of calls every month. It is the most wellorganized institution under the command of Dr. Rizwan Naseer, the service has well-equipped skill training centers, and an Emergency Services Academy, where first aid and CPR training is imparted to their employees, besides other emergency services. The instructors for this academy were initially trained through the Enhancement of Emergency Response (PEER) program of USAID to conduct Medical First Responder (MFR) course. Rescue 1122 has also started an ambitious 'Community Safety Program' which includes capacity building of community emergency response teams, school safety program, training of citizens in life saving skills. But the capacity of this organization in itself is not at a scale to make any visible impact on the community any sooner. ${ }^{7}$ This service is a role model and has provided technical assistance to emergency services in other provinces.

\subsection{CPSP}

We are lucky that College of Physicians \& Surgeons Pakistan started their life support training programs in 2014 and got accreditation by AHA for BLS and ACLS programs. The college website states that BLS course is aimed at everyone including healthcare providers, whereas ACLS is "designed primarily for general physicians, family healthcare providers, nurses, emergency medical technicians, paramedics, respiratory therapists, and other professionals who either direct or participate in the resuscitation of a patient, at the pre-emergencies, emergencies or in of hospital". It's an ambitious program and currently BLS has been declared mandatory for all the postgraduate candidates, and ACLS for the postgraduate candidates in selected specialties (e.g., anesthesiology, cardiology, cardiothoracic anesthesia etc.) and the potential postgraduate training supervisors (although the college website is silent on this topic). The courses are being conducted at regional centers as well. The certificates are valid for two years, after which these need to be renewed through refresher courses according to AHA policy. ${ }^{6,7}$

But there are few problems; firstly, although the number of accredited instructors affiliated with CPSP 
appears to be good (150+), not many of them are readily available to run the courses unless adequate incentives are offered. Perhaps for the same reason many of the fresh consultants are not interested in joining the instructor cadres. Secondly, CPSP does not maintain the database of all of the candidates, and there is no set protocol to follow the successful or the unsuccessful candidates to issue them reminders and ensure that every postgraduate has valid certificates all the time. The result is that the program cannot be termed as a fully dynamic one and useful to the profession in the real sense. We know that the skills learnt get blunted over a period of time. Thirdly, the CPSP has to charge a substantial amount from the participants to cater for the AHA course material, maintenance of equipment, and administrative reviews by AHA.

\subsection{Save Life Training Center}

Armed Forces Institute of Cardiology and National Institute of Heart Diseases (AFIC-NIHD) Rawalpindi, Pakistan has been involved in CPR training for more than two decades. The institute established 'Save Life Training Center' in 2015 and got accredited by AHA for BLS and ACLS courses, to spread the knowledge and skills of basic and advanced cardiac life support. It has not only served to train every healthcare professional of the institute, but also a large number of doctors and nurses from outside the institute. It follows you from registration to the completion certificate, but no more. ${ }^{8}$ The instructors conduct courses purely on voluntary basis; but the candidates have to pay a substantial fee like CPSP.

\subsection{Pakistan Resuscitation Society}

Pakistan Resuscitation Society (PARES) was started by the author back in 1999, while still serving in Pakistan Army. We conducted a series of BLS programs in different hospitals, but ultimately failed to get enough participants due to administrative hurdles, and the programs had to be abandoned for good. The society failed to attract an adequate number of willing enthusiasts to form a team, so remained alive in the mind of the author and continued to spread the current knowledge and latest information through a page on Facebook. $^{9}$

\subsection{Pakistan Medical \& Dental Council (PM\&DC)}

PM\&DC decided in May 2010 that BLS certification will be mandatory pre-requisite for house job. Unfortunately, this certification was left on the discretion of the medical colleges and there was no monitoring of the actual training imparted to the newly graduated doctors.

There are a total of 114 medical colleges in Pakistan, including 44 in public sector and 70 in private sector, recognized by PM\&DC. The annual seat allocation varies from 50 to 350 students per college every year. If an average of admissions per year is calculated, it may come to be about 200, which means that 22800 new medical students are being added to the medical colleges every year. ${ }^{10}$

Similarly, there are 55 dental colleges, 15 in public sector and 40 in private section, recognized by PM\&DC. ${ }^{11}$ These dental colleges have 50-100 seats each; that means an average of 70 seats per college. So, the number of fresh entrants every year is 3850 . It means approximately 26650 medical students enter the medical circle every year.

Unfortunately, except for a handful of medical / dental colleges, most colleges don't have a well-equipped skill lab. Most of the graduates don't have a chance to perform hands-on CPR. Only a handful medical colleges run mandatory BLS training programs for their students in the first two years; a valid certificate is mandatory for house jobs, induction in postgraduate training and even employment. Some medical institutions run training courses due to personal interest of some department heads. These programs are usually open-ended, without any follow-up and not restricted to own medical students or HCPs.

\subsection{Pakistan Resuscitation Council (defunct)}

There has been some effort to establish a central institution with the name of Pakistan Resuscitation Council in the past. Evidently, it had some eminent names from academic circles of Karachi as appointment holders, perhaps was registered as a society with the concerned department, launched a website, but miserably failed to take off probably due to lack of the required level of sincerity to the cause, the drive as well as the will to sacrifice time, effort and 
resources to launch it successfully. A website kept its name alive for a few years, then it vanished. Another name surfaced in the Google search is 'National Resuscitation Council of Pakistan'. It lives as a Facebook page created on September 7, 2013. The page is liked by 13 people, consists of only one post, dated September 7, 2013. ${ }^{12}$

\subsection{NGOs}

Few NGOs have been active in training resuscitation and conducting training courses across the country, usually on invitation by a medical institution. The most notable are BoschMedicus, Médecins Sans Frontières/Doctors Without Borders (MSF) and International Committee of Red Cross (ICRC). BoschMedicus is a subsidiary of Bosch Pharmaceutical Company, and delivers AHA certified programs customized for consultants, GPs, and all specialty hospital doctors across the country. It has played a pivotal role in establishing Save Life Training Center at AFIC/NICVD Rawalpindi. The company offers courses at nominal fee, has trained instructors and training material, but needs collaboration by some host institution to provide ground work and the facilities.

\subsection{Time to ponder}

It can be seen that the training efforts remain disorganized, non-systematic and have minimal effect on the patient survival. The result is that majority of our graduates as well as postgraduates lack basic and advance knowledge of cardiopulmonary resuscitation skills. A study by Zameer Q, et al. assessed the basic knowledge to be; junior doctors $44.75 \%$, senior doctors $45.5 \%$, dentists $23 \%$. The study found that the basic knowledge was in junior doctors $45.37 \%$, senior doctors $29.48 \%$ and the dentists $31 \%$. They concluded that the awareness of basic and advance knowledge of cardiopulmonary resuscitation skills in medical/dental students and doctors in Rawalpindi and Islamabad was inadequate. ${ }^{13}$ Another study presented similar conclusion for doctors, dentists and nurses of Karachi. ${ }^{14}$

An editorial in Journal of Pakistan Medical Association in a 2008 issue highlighted important weaknesses in the hospital care, particularly the emergency care of children in the hospital settings. The main areas of weaknesses note were an inadequate triage system, substandard, delayed and inappropriate assessment and treatment along with insufficient monitoring. ${ }^{15}$ The authors noted that pediatric resuscitation skills are essential for everyone involved in providing pediatric care. The authors suggested to establish a central body, such as a Resuscitation Council, to set standards and co-ordinate training programs and certification, and to make resuscitation training a statutory requirement

Resuscitation Council would need federal government approval to work as an independent institution to drive the healthcare institutes to provide an effective resuscitation service. It must also oversee the resuscitation training of the staff, besides issuing guidelines regarding availability of appropriate equipment, financial planning, and the quality issues and protocols. ${ }^{16}$

\section{Suggested plan}

Keeping the inadequate output by most of the public sector institutions, it seems highly unlikely that the suggested council will ever function as effectively as AHA or RC (UK) or ERC. Can we have any alternative arrangement? Yes, we can. The following paragraph depicts how to get the desired results in a decentralized model.

\subsection{Phase One}

BLS, and ALS certificate must be a statutory requirement for registration (or renewal of registration) with PM\&DC by every medical / dental graduate. Similarly, this must be a statutory requirement for applying for house job, or postgraduate training or service in public / private healthcare institution. To ensure adequate training facilities, we need to expand the facility base. We don't need AHA or ERC or similar accreditation by foreign institutions. Start it as suggested here, and the quality of the training will gradually improve to the desired level. 'Something is better than nothing' and 'a poor-quality resuscitation is better than no resuscitation'.

- $\quad$ Every medical / dental college must have an advanced skill lab, containing all the manikins for hands-on training in BLS, ALS, Paediatric Advanced Life Support (PALS), and Advanced Life Support in Obstetrics (ALSO). 
- The advanced skill lab must be headed by a Resuscitation Officer (RO), who, in turn should be directly under Director Medical Education (DME) / Principal / Dean. ROs would be responsible to conduct and coordinate all training activities.

- The responsibility of BLS training and certification to be delegated to the physiology departments. The course may take only 3-4 hours. Adequate information technology (IT) equipment and trained staff be provided, so that the department could work as the nerve center of BLS training.

- Every medical student be trained in BLS during first year (before first professional exam) in the college and issued a valid certificate, to be revalidated after every two years.

- ALS, PALS courses should be the responsibility of anesthesiology, cardiology and pediatrics departments. The certification responsibility might be delegated to one wellstaffed department.

- ALS and PALS training may start from the second half of third year, and should continue through fourth and fifth years. Certificates will be issued for two years, and the holders must go a refresher course within three months after the expiry of the certificate.

- ALSO should be the responsibility of anesthesiology and Obstetrics \& Gynecology departments. The certification responsibility might be delegated to either department. ALSO training may start from the fourth year. The certificate must be revalidated within three months of expiry.

- Only the doctors with valid BLS, ALS / PALS / ALSO should be allowed to enter house job.

\subsection{Phase Two}

The above-mentioned departments must also train some nursing staff to act as instructors in BLS, ALS, PALS and ALSO. After that nursing school should take up the responsibility of training and certification / recertification of nursing staff. Every nursing school must have a designated RO to conduct and coordinate training activities.

\subsection{Phase Three}

With adequate number of full qualified instructors, paramedical staff and support staff can be trained in BLS. Certification and recertification will be the responsibility of the nursing school with the help of anesthesiology and cardiology departments.

\subsection{Pakistan Resuscitation Council}

Currently three most active institutions in the field of resuscitation training, e.g., CPSP, AFIC and AKUH must host a comprehensive database of all training activities related to resuscitation. The registered resuscitators should be issued reminders to register for refresher courses. These three institutions may join hands and form a nucleus to lay down the foundation of semi-autonomous body by the name of Pakistan Resuscitation Council, with federal government charter and some permanent staff. The council must formulate standardized training programs for all the resuscitation courses focusing on lesson plans, skill practice, skill testing and instructor training. These standardized training programs then should be implemented through PM\&DC and CPSP all over the country.

Federal government and Higher Education Commission (HEC) may allocate the required funds for the council in their annual budgets.

\subsection{Phase Four}

Pakistan Resuscitation Council, once fully functional, should train two or three school / college teachers to function as RO's in every school / college. Physical training (PT) teachers should be given preference. Every student must undergo basic training in CPR. CPR must be included in the curriculum of the primary as well as high school.

\section{Conclusion}

Resuscitation training has been neglected far too long by our health authorities. Every higher regulatory or academic institution has played a role in this sad state of affair, in which our junior and senior doctors, dentists and nurses come up with highly inadequate knowledge about resuscitation. This factor alone might well be responsible for millions of avoidable deaths of in-hospital cardiac arrest victims after poor 
performance by the healthcare professionals. We need to have a professional body (Pakistan Resuscitation Council) at the federal level to coordinate all trainings and guidelines pertaining to resuscitation. PM\&DC and CPSP must make valid certification as a statutory requirement for registration and to hold any academic or administrative post in any public or private medical institution.

Let us stand in the ranks and files of the developed nations with a high head. The day will come when every citizen of this country will be able to act promptly and save the lives of witnessed cardiopulmonary arrest due to any cause.

\section{Acknowledgements}

The author offers his sincere gratitude to Brig Rashad Siddiqui, Consultant Cardiac Anesthesiologist and Senior Instructor, Save Life Training Center, AFIC/NICVD, Rawalpindi, Pakistan, for his valuable, suggestions, additions and corrections in the manuscript.

\section{Conflict of interest}

Nil declared by the author

\section{Author's contribution}

THK is the sole author, from inception of the idea to the final preparation of the manuscript.

\section{References}

1. World Health Organisation, Cardiovascular diseases. [Internet] Available from: https://www.who.int/healthtopics/cardiovascular-diseases/\#tab=tab_1 (Accessed on 6 August 2020).

2. Khan K, Aziz S, Saif M, Kamran J, Rauf A, Khalid W, Mazhar M. Pattern of coronary artery disease in asymptomatic serving soldiers having abnormal screening ETT. PAFMJ [Internet]. 29 Nov.2019 [cited 13 Aug.2020];69(Suppl-3):S354-358. Available from: https://pafmi.org/index.php/PAFMJ/article/view/3540

3. Chaudhry MA, Waseem M, Ahmad F, Ashraf MZ, Bhatti A. Frequency of Coronary Heart Disease: Risk Factors among Doctors of $\mathrm{CMH}$ Lahore Medical and Dental College, Lahore - Pakistan. Annals Punjab Med College 2012;6(2):56-60 [Free full text]

4. CPR Facts \& Stats: How CPR is changing (and saving) lives [Internet] Available from: https://cpr.heart.org/en/resources/cpr-facts-and- stats\#: :text=More $\% 20$ than $\% 20350 \% 2$ C000\%20cardia c\%20arrests, a \%20person's\%20chance $\% 20$ of $\% 20$ survi val. (Accessed on 6 August 2020)

5. Advanced Skill Department: BLS $®$ (Basic Life Support) Program [Internet]. Available from https://www.cpsp.edu.pk/bls-program.php (Accessed on 6 August 2020)

6. Advanced Skill Department: ACLS $®$ (Advanced Cardiac Life Support) Program [Internet]. Available from: $\quad$ https://www.cpsp.edu.pk/acls-program.php (Accessed on 6 August 2020)

7. Punjab Emergency Service: Introduction of Rescue 1122 [Internet]. Available from: http://www.rescue.gov.pk/Introduction.aspx (Accessed on 5 August 2020)

8. Save Life Training Center [Facebook] Available from: https://www.facebook.com/pg/savelifepakistan/about/?r ef=page_internal

9. https://www.facebook.com/pakresus/ (Accessed on 4 August 2020)

10. Pakistan Medical \& Dental Council: Recognized medical colleges in Pakistan. [Internet]. Available from:

http://www.pmdc.org.pk/AboutUs/RecognizedMedicalD entalColleges/tabid/109/Default.aspx (Accessed on 5 August 2020)

11. Pakistan Medical \& Dental Council: Recognized dental colleges in Pakistan. [Internet]. Available from:

http://www.pmdc.org.pk/recognizeddentalcollegesinpak istan/tabid/167/default.aspx (Accessed on 5 August 2020)

12. National Resuscitation Council of Pakistan. Available from: $\quad$ https://www.facebook.com/NationalResuscitation-Council-of-Pakistan1414983538714942/ (Accessed on 6 August 2020)

13. Zamir Q, Nadeem A, Rizvi AH. Awareness of cardiopulmonary resuscitation in medical-students and doctors in Rawalpindi-Islamabad, Pakistan. J Pak Med Assoc. 2012;62(12):1361-1364 [PubMed] [Free full text]

14. Irfan B, Zahid I, Khan MS, Khan OAA, Zaidi S, Awan S, et al. Current state of knowledge of basic life support in health professionals of the largest city in Pakistan: a cross-sectional study. BMC Health Serv Res. 19, 865 (2019). [Internet] Available from https://doi.org/10.1186/s12913-019-4676-y (Accessed on 6 August 2020) [Free full text]

15. Nolan $T$, Angos $P$, Cunha A, Muhe L, Qazi S, Simoes $E A$, et al. Quality of hospital care for seriously ill children in less developed countries. Lancet 2001;357:106-110. [PubMed] DOI: 10.1016/S0140-6736(00)03542-X

16. Sheikh-Sajjad AR, Razzak JA. The need for formal paediatric resuscitation training in Pakistan. J Pak Med Assoc. 2008;58(2):51-52. [PubMed] [Free full text] 